\title{
POTRET INTEGRASI ISLAM DAN BUDAYA NUSANTARA DI ERA WALISONGO
}

\author{
Hamdan Adib \\ Universitas Islam Negeri Prof KH Saifuddin Zuhri \\ E-mail: adib.hamdan123@gmail.com
}

\begin{tabular}{|c|c|c|}
\hline Received & Revised & Accepted \\
\hline 4 July 2021 & 2 Agustus 2021 & 20 September 2021 \\
\hline
\end{tabular}

\section{PORTRAIT OF INTEGRATION OF ISLAM AND CULTURE OF THE WALISONGO ERA}

\begin{abstract}
Until now this form is still a lot of cultural forms in question because it is not the original innate religion of Islam in Arabia. The existing culture in Indonesia, some have stated and acknowledged that culture is a feature of Islam in Indonesia by some others being opposed because there is no historical or Naqli argument to prove it So in this study, it will be explained about the study of integration in this archipelago which began in the Walisongo era and has existed until now. The method used in this research is qualitative library research where researchers will conduct a study into various literatures related to Islam and Culture in the archipelago from various documents. The results found are Islam in Java where the Javanese community still maintains tahlilan, slametan and the culture attached to the community which has fruited its value from what was originally a Hindu-Buddhist pattern turned into Islamic, besides that the pesantren education system also colors this integration, Islam in Sumatra is supported by three forces, namely pesantren, markets and palaces, and Islam in eastern Indonesia was carried out by students from one of the walisngo in Java. Through this research, it will be found both theoretically regarding the integration of Islam and the culture of the archipelago as well as the practices that occur.
\end{abstract}

Keywords: integration, Archipelago Culture, and Walisongo era.

\begin{abstract}
Abstrak
Sampai dengan saat ini bentuk ini masih banyak sekali bentuk budaya yang dipermasalahankan karena bukan bawaan asli agama Islam yang ada di Arab. Budaya yang ada di Indonesia yang seberapa bagian sudah menyatakan dan mengakui bahwa budaya itu menjadi ciri Islam yang ada di Indonesia oleh sebagian lainnya di tentang karena memang tak ada dalil sejarah ataupun Naqli yang membuktikannya. Maka dalam penelitian ini akan dijelaskan mengenai kajian integrasi yang ada di Nusantara ini yang dimulai sejak era walisongo dan eksis sampai dengan sekarang. Metode yang digunakan dalam penelitian ini yaitu kualitatif library research dimana peneliti akan melakukan kajian ke dalam berbagai literatur yang berkaitan dengan Islam dan Budaya yang ada di Nusantara dari berbagai
\end{abstract}


dokumen. Hasil yang ditemukan yaitu islam di jawa dimana masyarakat jawa masih mempertahankan tahlilan, slametan dan budaya yang melekat pada masyarakat yang sudah berbuah nilainya dari yang awalnya bercorak hindu budha berubah menjadi Islami, selain itu sistem pendidikan pesantren juga mewarnai integrasi ini, islam di sumatra yang didukung oleh tiga kekuatan, yaitu pesantren, pasar dan istana, serta islam yang ada di Indonesia timur dilakukan oleh murid-murid dari salah satu walisngo yang ada di pulau Jawa. Melalui penelitian ini maka akan ditemukan baik secara teoritik mengenai integrasi Islam dan budaya nusantara serta praktik yang terjadi.

Kata Kunci: integrasi, budaya Nusantara, dan zaman Walisongo.

\section{Pendahuluan}

Melihat realitas budaya yang terjadi saat ini, sudah banyak sekali budaya yang awalnya bukan suatu identitas masyarakat atau agama tertentu, menjadi identitas yang melekat kepada masyarakat tersebut. Misalnya saja genduri bagi orang yang sudah meninggal, yang awalnya merupakan budaya dari masyarakat Indonesia yang beragama Hindu karena disatukan dengan nilai Islam dan muatanya diganti dengan muatan Islam dengan tidak mengganti secara total mengenai praktik yang dilakukan dan kini menjadi salah satu ciri masyarakat muslim di Nusantara. Ini merupakan integrasi yang dilakukan dalam bidang kebudayaan. Maka dari itu integrasi juga bisa dipahami dengan proses mempersatukan hal hal yang saling berbeda/terpisah. Proses mempersatukan hal yang terpisah ini tidak secara langsung terjadi, namun melewati tahapan-tahapan yang harus dilalui. Tahapan tahapan ini menjadi dasar untuk terlaksananya tahapan berikutnya.

Integrasi juga memungkinkan terjadinya konflik antar satu hal dan hal lain yang saling diintegrasikan. Konflik ini akan membentuk integrasi yang terjadi apakah akan menjadi integrasi seutuhnya ataukan hanya saling berdialogis. Keberhasilan integrasi yang dilakukan bergantung kepada sejauh mana pengintegrasi berfikir cerdas dan sejauh mana keberbedaan antar hal itu. Semakin banyak, kompleks dan fundamental hal yang saling berbeda, akan sangat sulit dua hal itu diintegrasikan. Oleh karena itu harus diperhatikan dengan seksama antara apa yang akan diintegrasikan ini.

Dewasa ini integrasi Islam dan budaya nusantara khususnya yang di gaungkan oleh salah satu organisasi Islam yaitu NU menjadi pelopor terbentuknya integrasi yang mampu menjadi penengah antara ekstrim logika dan ekstrim agama. Islam nusantara menjadi model integrasi yang humanis dan menjadi percontohan bagi masyarakat dunia. hal ini sama yang dengan yang dilakukan oleh Walisongo dalam membawa Islam, dimana Islam tidak dibawa dengan kekerasan namun dengan akulturasi dan integrasi budaya yang ada di masyarakat Jawa, hasilnya Islam dapat di terima dengan tangan terbuka dan menjadi agama mayoritas di bumi Nusantara.

Bentuk integrasi ini kiranya perlu dilihat lebih dalam lagi mengenai bagaimana terbentuknya dan praktik-praktik yang tersebar di penjuru nusantara. Selain itu di dalam penelitian ini jangkauan yang dikaji tidak hanya berpusat pada pulau Jawa seperti yang biasa dilakukan oleh beberapa peneliti, mewakili Sumatra dan bagian timur indonesia. Khabib M Luthfi dalam penelitiannya menjelaskan mengenai relasi Islam dan Budaya Nusantara yang dirangkum ke dalam Islam Nusantara dimana dia mengatakan bahwa terdapat berbagai pendekatan yang digunakan para intelektual 
NU dalam menjelaskan relasi ini yaitu filsafat, budaya, lingkuistik, hukum, historis, fisiologis, sosiologis, dan muti pendekatan ${ }^{1}$. Selain itu dalam penelitian yang dilakukan Muhammad Harmain mengatakan bahwa dalam akulturasi yang dilakukan Islam dengan budaya lokal Islam sudah lebih dulu memahami setting yang ada sehingga eksistensi Islam ketika berakulturasi dapat diterima masyarakat. ${ }^{2}$ Melalui penelitian ini peneliti mendeskripsikan dan menganalisis bentuk integrasi Islam dan budaya yang ada di nusantara,

\section{Metode Penelitian}

Penelitian menggunakan metode penelitian kualitatif dengan jenis penelitian pustaka atau library research, dimana penelitian ini merupakan suatu penelitian yang dilakukan di perpustakaan untuk menghimpun, mengolah, menganalisis data yang bersumber dari perpustakaan yang berupa jurnal, buku, majalah, surat kabar dan sumber lainnya ${ }^{3}$. Tujuannya adalah untuk mengumpulkan data dan informasi dengan bantuan materi yang terdapat di ruang perpustakaan berupa literaturliteratur. Dominasinya penelitian ini digunakan pada penelitian sejarah dan juga bahasa.

Analisis yang digunakan dalam penelitian ini yaitu konten analisis yaitu penelitian yang dilakukan dengan melihat dokumen tertulis, baik dalam bentuk digital maupun percetak ${ }^{4}$. Analisi konten yang digunakan pada penelitian kali ini yaitu analisis konten summative, analisis konten ini digunakan untuk memahami kata yang muncul dengan tujuan untuk memahami cara penggunaan kata secara kontekstual. Kuantifikasi kata yang muncul bukan digunakan sebagai cara untuk mengambil kesimpulan namun hanya untuk mengeksplorasi penggunaanya. Jika penelitian ini juga dilakukan dalam proses interpretasi atas konten ${ }^{5}$.

Pada penelitian kali ini peneliti mencari informasi dan data berbagai hal yang berkaitan dengan integrasi Islam dengan budaya yang ada di Nusantara era walisono dilihat dari sisi sejarahnya.

\footnotetext{
${ }^{1}$ Khabibi Muhammad Luthfi, “Islam Nusantara: Relasi Islam Dan Budaya Lokal," SHAHIH: Journal of Islamicate Multidisciplinary 1, no. 1 (2016): 1-12.

2 Limyah Al-Amri and Muhammad Haramain, "Akulturasi Islam Dalam Budaya Lokal," KURIOSITAS: Media Komunikasi Sosial Dan Keagamaan 10, no. 2 (2017): 87-100.

${ }^{3}$ S Riyanto and A A Hatmawan, Metode Riset Penelitian Kuantitatif Penelitian Di Bidang Manajemen, Teknik, Pendidikan Dan Eksperimen (Deepublish, 2020).

${ }^{4}$ A.D.I.F.H. Ujang Sumarwan, Metode Riset Bisnis Dan Konsumen Edisi Revisi (PT Penerbit IPB Press, 2018).

${ }^{5}$ Jogiyanto Hartono M, Metoda Pengumpulan Dan Teknik Analisis Data (Penerbit Andi, n.d.).
} 


\section{Hasil dan Pembahasan Kajian Integrasi}

Integrasi diartikan sebagai menyatu padaukan, mempersatukan atau menggabungkan ${ }^{6}$. Integrasi berasal dari bahsa inggris yaitu integration yang memiliki arti penyatuan supaya menjadi suatu kebetulan atau menjadi utuh ${ }^{7}$.

Selain definisi diatas ada beberapa definisi lainya mengenai integrasi, yaitu:

Integration is defined as the act or proccess of integrating: such as incorporation as equals into society or an organization of individuals of different groups ${ }^{8}$.

Huntley's "Definition is more specific about how connections between disciplines can be made. She explains that, in integrated instruction, concepts from more than one discipline are explicitly assimilated"9

Dari beberapa definisi diatas dapat disimpulkan bahwa integrasi adalah penyatuan dua atau lebih hal yang memiliki perbedaan sifat, bentuknya sehingga menjadi satu kesatuan yang utuh.

Maka jika berbagai macam budaya dengan karakteristik yang berbeda menjadi satu dengan cara akulturasi, dialogis atau terintegrasi secara penuh kemudian menciptakan satu kebudayaan baru maka ini dinamakan dengan integrasi budaya. Maka dalam integrasi ini point penting yang perlu dipahami adalah adanya komunikasi atau sentuhan dua budaya atau lebih berbeda.

Melihat kemampuan manusia yang mampu menyatukan serta menciptakan budaya baru maka hal ini memperlihatkan manusia bukan hanya makhluk biologis biasa, namun manusia memiliki kelebihan seperti yang dijelaskan didalam al Qur'an. atau bisa dikatakan juga dengan manusia adalah makluk budaya (homo kulturalis), dikatakan demikian karena dalam memenuhi hasrat kepuasanya, manusia tidak hanya harus memnuhi kebutuhan biologisnya, namun juga kebutuhan akan pemenuhan makna didalam hidupnya yang membawa manusia kepada mitos, seni, ritus, bahasa, ilmu dan semua gejala lainya. dalam proses pemenuhan makna ini kadang manusia memerlukan perpaduan antar satu term dengan yang lainya, misalnya tentang aturan budaya yang ada di lingkunganya dengan aturan agama.

Paradigma Integrasi didalam Islam diawali dengan proses integrasi keilmuan yang menjadi sampai sekarang masih selalu di update konsep yang benar-benar baik dan mampu menjadi pemicu berkembangnya keilmuan yang ada di zaman ini. Integrasi keilmuan ini juga menjadi ciri khas dari tiap universitas khususnya dalam memberikan corak integrasi yang dilakukan di lembaga tersebut. Ada beberapa tipe pemaknaan integrasi keilmuan yaitu: 1) Integrasi dimaknai dengan penggabungan ilmu umum dan agama sehingga bersatu menjadi kesatuan ilmu yang tak terpisahkan. 2) Integrasi juga dimaknai dengan Islamisasi ilmu pengetahuan umum.

\footnotetext{
${ }^{6} \mathrm{M}$ S Ismail and M S Sri Hartati, PENDIDIKAN KEWARGANEGARAAN: Konsep Dasar Kehidupan Berbangsa Dan Bernegara Di Indonesia (Penerbit Qiara Media, 2020).

${ }^{7}$ A Nata, Islam Dan Ilmu Pengetahuan (Prenada Media, 2018).

${ }^{8} \mathrm{C}$ Rabe-Hemp et al., Women Policing across the Globe: Shared Challenges and Successes in the Integration of Women Police Worldwide (Rowman \\& Littlefield Publishers, 2019).

${ }^{9}$ L Bindel, Effects of Integrated Learning: Explicating a Mathematical Concept in Inquiry-Based Science Camps, Studien Zum Physik- Und Chemielernen (Logos Verlag Berlin, 2018).
} 
3) Integrasi ilmu hanya dimaknai secara simbolik, hanya memberikan peluang kepada ilmu lain untuk tetap dipelajari dan tetap berjalan apa adannya ${ }^{10}$.

\section{Budaya Nusantara}

Budaya dalam kajian etomologi berasal dari kata bodhaya yang memiliki arti akal budi. Budaya diartikan sebagai segala hal yang dibuat manusia berdasarkan pikiran dan akal budinya yang mengandung cinta dan rasa" .

Budaya dikenal dengan istilah lain yaitu adat istiadat merupakan segenap pengetahuan, nilai-nilai, pandangan hidup, ritual dan praktik kesehariab, baik yang tertulis ataupun tidak tertulis dan telah teraplikasikan dalam keseharian masyarakat ${ }^{12}$.

Budaya juga diartikan sebagai karakteristik dan pengetahuan suatu group tertentu, melipti bahasa, kepercayaan, makanan, kebiasaan sosial, musik dan seni ${ }^{13}$.

Jadi bisa dikatakan bahwa budaya nusantara merupakan bentuk kebiasaan, kepercayaan, alat alat kehidupan yang terjadi dan dihasilkan di nusantara dan oleh masyarakat nusantara.

Nusantara dalam artian luas diartikan sebagai semua wilayah yang telah di taklukan oleh kerajaan majapahit dalam sumpah palapa oleh gajah mada, namun dalam kajian ini, term nusantara didasarkan kepada wilayah Indonesia dengan banyak sekali daerah dengan berbagai kulturnya. Salah satu daerah yang menjadi kajian utama dalam perkembangan budaya dan integrasinya dengan Islam adalah pulau Jawa, meskipun didalam sejarah masuknya Islam ke Indonesia berasal dari Aceh dengan kerajaan samudera pasainya namun ternyata kajianya tidak sepopuler integrasi budaya yang dilakukan oleh Walisongo di pulau Jawa. Setelah itu ada budaya melayu dengan integrasi Islamnya samapi kepada sistem pemerintahan seperti yang terjadi di maksar.

Unsur unsur yang ada didalam budaya terbagi menjadi empat bagian, yaitu alat teknologi, sistem ekonomi, keluarga dan kekuasaan politik. Bronislaw Malinowski juga memberikan pendapat mengenai unsur kebuayaan yaitu: 1) Sistem norma yang memungkinkan kerjasama antar para anggota masyarakat di dalam upaya menguasai alam sekelilingnya, 2) Organisasi ekonomi, 3) Alat-alat dan lembaga atau petugas pendidikan, perlu diingat bahwa keluarga merupakan lembaga pendidikan yang utama, 4) Organisasi kekuatan.

Jika melihat bahwa budaya merupakan cipta dan karsa manusia, maka budaya memiliki karakteristik yaitu: 1) Culture is an adaptive mechanisme, (budaya adalah suatu mekanisme yang dapat menyesuaikan diri), 2) Culture is learned, (budaya diperoleh melalui belajar), 3) Culture change (budaya akan berubah) ${ }^{14}$

\footnotetext{
${ }^{10}$ L Hakim, Pendidikan Islam Integratif: Best Practice Integrasi Pendidikan Agama Islam Dalam Kurikulum Pendidikan Tinggi (Gestalt Media, 2020).

${ }^{11}$ A Fuadi, Keragaman Dalam Dinamika Sosial Budaya Kompetensi Sosial Kultural Perekat Bangsa (Deepublish, 2020).

${ }^{12}$ A Rasyidin, Percikan Pemikiran Pendidikan: Dari Filsafat Hingga Praktik Pendidikan (Citapustaka Media Perintis, 2009).

${ }^{13} \mathrm{M}$ F Juddi, KOMUNIKASI BUDAYA DAN DOKUMENTASI KONTEMPORER (Unpad Press, 2019).

${ }^{14}$ S.S.M.S. Sriyana, Antropologi Sosial Budaya (Penerbit Lakeisha, 2020).
} 
Meskipun budaya merupakan kehendak yang dicurahkan dalam bentuk benda atau aktivitas bukan berarti budaya tidak memiliki problematika didalamnya, Elly Maliha menjelaskan beberapa probelmatika dalam kebudayaan yaitu: 1) Hambatan budaya yaitu berkaitan dengan sistem kepercayaan dan pandangan hidup, 2) Hambatan budaya yaitu perbedaan tentang sudut pandang, 3) Hambatan budaya yaitu berkaitan dengan kejiwaan, 4) Kurangnya komunikasi dengan masyarakat secara luas sehingga suatu masyarakat menjadi terasing, 5) Sikap yang sellau berperasangka buruk terhadap hal baru, 6) Sikap etnosentrisme, 7) Penyalahgunaan pengembangan ilmu pengetahuan oleh manusia, 8) Culture shock atau gagap budaya, atau tidak mampunya orang lain atau penerus dalam beradabtasi dengan budaya baru ${ }^{15}$.

\section{Islam dalam Konteks Budaya Jawa}

Cerminan masyarakat yang ideal yaitu masyarakat yang tidak menafikan perbedaan, contoh yang paling representatif masyarakat ideal adalah masyarakat madinah yang disatukan oleh piagam madinah. Piagam ini tidak dibuat untuk kepentingan sesaat saja, namun juga menjadi pedoman pelaksanaan pemerintahan sesuai dengan yang dicontohkan oleh Nabi saw. begitu juga seharusnya cerminan masyarakat yang ada di nusantara. Apalagi agama yang tersebar di nusantara merupakan agama yang bukan berasal dari nusantara, India menyumbang agama Hindu, gabungan antara China dan India menyumbang agama Budha, dan Timur Tengah menyumbang agama Islam dan Kristen ${ }^{16}$. Tanah Jawa sendiri sebenarnya sudah memiliki agama asli yang dikenal dengan Kapitayan, agama Kapitanyan mempercayai adanya roh yang berada di luar dirinya sebagai penguasa. Para Islamolog memberikan nama lain yaitu agama sinkretik. Sehingga Walisongo dengan kesadaran akan hal ini menggunakan metode toleran dan mengahragai tradisi lokal dalam melaksanakan dakwahnya.

Salah satu budaya yang masih di pegang erat oleh masyarakat Jawa adalah slametan. Kata slamet sendiri menurut Greetz merupakan nilai Jawa yang sangat penting dan memili makna yang lengkap. Kata ini memiliki kompilasi makna yang terdiri dari sejahtera, makmur, aman, dan terlindungi dari berbagai macam bahaya alam dan adikodrati ${ }^{17}$. Masyarakat Jawa sendiri memandang kata slametna merupakan perwakilan keinginan manusia kaitanya dengan Tuhan dan alam semesta. Dimulai dari kata selamet ini masyarakat Jawa mengimplementasikanya kedalam berbagai ritual, ada ritual tingkeban (yaitu ritual yang dilakukan ketika sebuah keluarga sedang hamil anak pertama pada usia tujuh bulan), babaran, pasaran, pitonan, dan lain-lain ${ }^{18}$. Ada juga upacara kematian, perkawinan, panen dan lainya yang intinya mencari dan mengharapkan keselamatan atau selamet.

\footnotetext{
${ }^{15}$ Adli Abdullah Teuku Muttaqin Mansur, Sulaiman and Hasbi Ali, Ilmu Sosial Dan Budaya Dasar: Berbasis General Education (Syiah Kuala University Press, 2020).

${ }^{16}$ V T King and W D Wilder, The Modern Anthropology of South-East Asia: An Introduction, Modern Anthropology of South-East Asia (RoutledgeCurzon, 2003).

${ }^{17}$ C Geertz, The Religion of Java, Center for International Studies (Free Press, 1960).

${ }^{18}$ Geertz.
} 
Selain mengenai slametan ada beberapa budaya bangsa yang melekat dan saling terhubung dengan budaya lain, yaitu penggunaan kalender Jawa yang jika di dikaji secara historis merupakan hasil dari gabungan budaya Islam dan Hindu yaitu pada kalender saka dengan sistem bulan (Qomariyah). Nama Arab untuk 12 bulan juga ditampilkan dengan rasa Jawa namun diantaranya masih menggunakan negasi Arab, seperti berurut dari bulan pertama yaitu suro untuk muharram, sapar untuk shafar, maulud, bakdo mulud untuk robi'ul tsani, jumadl awal untuk jumad ula, untuk jumadil tsani, rejeb untuk rojab, ruwah untuk sya'ban, poso untuk ramadhan, sawal untuk syawal, selo untuk dzul qa'dah dan besar untuk Zulhijjah ${ }^{19}$. Akulturasi ini memberikan makna bahwa Islam mengikuti arus budaya Jawa dan berjalan beriringan tanpa merasa mendahului atau tertinggal.

Budaya fisik yang masih terlihat adalah makam-makam di tanah Jawa yang mengguanakan kaligrafi Arab dengan dua patok diatasnya, kemudian di setiap masjid dan mushala ada bedug dan kentongan dimana dua alat ini merupakan identitats dari masyarakat Jawa pada masa Hindu Budha, bahkan pondok pesantren yang memiliki ruang khusus santri untuk beristirahat dan tempat tinggalnya dengan bimbingan seorang kiai disebut sebagai pengambilan ide dari padepokan-padepokan Hindu Budha dimasa lalu yang dikenaldengan nama pusat belajar agama.

Pondok pesantren masa sekarang berkembang dan terbagi menjadi dua bentuk besar yaitu pesantren salaf dan kholaf. Pesantren salaf yaitu pesantren yang kajian di dalamnya merupakan kitab kitab kuning dan tidak ada kaitanya dengan pelajaran yang lain misalnya pelajaran umum, sehingga pelajaran yang diberikan murni dari kitab kitab karangan tokoh terdahulu. Dalam pengajaranya penggunaan kalimat Jawa dan tanda Jawa digunakan sebagai simbol dalam mempermudah pelaksanaan pembelajaran, misalnya kalimat utawi untuk menunjukan mubtada dan disingkat dengan huruf mim panjang, kemudian iku untuk menunjukan khobar dan disingkat dengan huruf kho'. Penggunaan istilah ini memberikan kemudahan bagi santri yang mengkaji kitab-kitab salaf di pondok pesantren. Model pembelajaran sorogan bandongan yang digunakan juga merupakan warisan pelaksanaan pembelajaran masa lalu yang masih eksis sampai sekarang.

Pelaksanaan pelaksaan akulturasi yang dilakukan oleh Walisongo dengan mempertahankan budaya nusantara yang ada baik dari perilaku maupun bentuk fisik merupakan bukti bahwa pelaksanaan dakwah yang dilakukan Walisongo tidak langsung menyalahkan dan menghujat tradisi masyarakat yang tidak sejalan dengan tradisi Islam sekalipun itu berbentuk pemujaan terhadap entitas yang adikodrati, hal ini merupakan strategi yang dilakukan Walisongo dalam mendekati masyarakat sekaligus mengenalkan Islam dengan lemah lembut agar dapat diterima dan tidak malah menjauhkan Islam dari masyarakat. Disinilah sikap arif terlihat dalam menerima realitas kondisi psikologis dan sosial masyarakat sebagai sebuah bentuk kesadaran bahwa setiap idnividu atau komunitas memiliki karakter yang tidak lepas dari proses pembentukan lingkungan. Jika ada dari masyarakat muslim atau dai yang memiliki keinginan untuk berdakwah dengan tujuan memberikan arahan kepada jalan yang lurus yaitu jalan yang sesuai dengan petunjuk Allah swt. harus dilakukan

\footnotetext{
${ }^{19}$ Mudhofir Abdullah, "Pribumisasi Islam Dalam Konteks Budaya Jawa Dan Integrasi Bangsa," Jurnal IndoIslamika 4, no. 1 (2014): 67-90.
} 
dengan cara yang penuh lemah lembut, menunjukan rasa kasih sayang sebagai bukti bahwa Islam menghormati dan menghargai realitas apapun yang telah ada di masyarakat. Hal ini juga dilakukan oleh jaman Nabi saw. ketika ada seseorang yang ingin masuk Islam namun tidak bisa meninggalkan kebiasaan mencurinya, nabi saw membolehkan dia masuk Islam. namun ada beberapa sahabat yang keberatan akan hal itu karena seperti nabi membolehkan mecnuri kemudian Nabi menjawab bahwa beliau tidak membolehkan mencuri namun membolehkan dia masuk Islam. karena nanti ketika dia memeluk Islam dengan hati dan fikiran yang semakin baik, dia akan meninggalkan kegiatan mencuri itu karena dilarang oleh agama dan tidak sesuai dengan hati nurani yang baik. Hal lain yang merupakan bentuk bertahap dalam berdakwah adalah hadits dilarangnya ziarah, karena keimanan orang Islam yang belum kuat dan kemudian dinaskh oleh hadits lain yang membolekan kegiatan ziarah.

Selain keberhasilan keberhasilan integrasi Islam dan budaya nusantara khsuusnya Jawa, ada juga ganjalan atau entrupsi dalam pelaksanaan akulturasi ini yaitu pelaksanaan hukuman yang diberikan kepada Syeh Siti Jenar oleh beberapa Walisongo sebagai pembela ortofoksi. Dalam kisah yang dijelaskan oleh Achmad Chodijin salah satu wali yang memang benar benar merupakan keturunan Jawa yaitu Sunan Kalijaga tidak menyetujui mengenai hukuman mati yang akan diberikan kepada syeh siti jenar karena mempraktikan sufistik falsafi atau dikenal dengan mistik di term Jawa. Jika melihat dakwah yang dilakukan oleh sunan kalijaga, beliau berdakwah dengan cara menfsirkan dan menampilkan Islam dengan perspektif kearifan lokal Jawa yang sebagianya tidak begitu jauh dengan pendekatan yang dilakukan oleh siti jenar. Namun hal selanjutnya terjadi kembali ketika kaum abangan yang diekcam oleh kalangan ortodoks akibat mempraktikan sinkretisme Islam. dalam kajian historis puncak perseteruan antara kaum abangan dan santri terjadi pada peristiwa G30/S PKI yang terjadi pada tahun 1965 dimana terjadi pembunuhan yang disinyalir dilakukan oleh kaum santri kepada kaum abangan yang berafilisi pada orgnisasi Islam dilakukan di sejumlah daerah di pulau Jawa ${ }^{20}$. Dalam historis Islam sendiri terdapat sekte radikal seperti khawarij yang memberikan gambaran terjadinya ketegangan sampai dengan pertumpahan darah pada masa sohabat.

\section{Islamisasi Budaya di Tanah Melayu}

Tanah melayu yang pada saat ini lebih dikenal dengan nama Sumatra merupakan salah satu bagian nusantara yang dalam salah satu kajian sejarah lebih dahulu disinggahi agama Islam sejak sebelum adanya Hindu buda di Nusantara. Jika ditinjau dari sejarah yang ada, secara umum bangsa melayu mengalami empat fase sejarah yitu pra Hindu-Budha, Hindu Budha, Islam dan kolonialisme ${ }^{21}$. Dalam perkembangan selanjutnya dari masa Hindu Budha adalah masa Islam, dimana kedatangan Agama Islam ini disambut baik oleh masyarakat tanah melayu hal ini karena Islam memiliki karakter yang egaliter dan populis, tidak dikenal sistem kasta

\footnotetext{
${ }^{20}$ Abdullah.

${ }^{21}$ M A Mudra, Redefinisi Melayu: Upaya Menjembatani Perbedaan Konsep Kemelayuan Bangsa Serumpun, 2013.
} 
dan kependetaan makin memungkinkan keterlibatan semua lapisan masyarakat dalam seluruh aspek kehidupan.

Penyebaran Islam pada masyarakat melayu didukung oleh tiga kekuatan yaitu istana, pesantren dan pasar. Dengan dukungan tiga kekuatan ini pengaruh Islam pada masyarakat melayu sangat potimal. Melalui pesantren dan pasar Islam disebarkan dan mempengaruhi secara kultur, dimana pesantren dan pasar merepresentasikan dengan pendidikan dan perdagangan. Kemudian secara politik legitimasi oleh istana. Inilah peran istana dalam penyebaran agama Islam di wilayah Sumatra.

Kemudian pesantren di Sumatra dikenal dengan kata dayah atau meunsah yang terkenal dan masyhur di Aceh kemudian surau di minangkabau kadang surau disama artikan dengan langgar yaitu bentuk lain dari masjid yang memiliki ukuran lebih kecil dan kapasitas makismalnya biasanya hanya berkisar 15-20 orang. Lembaga ini semakin banyak dan menjamur pada abad ke 18 dan menjaddi pusat dari kegiatan thariqat (tarekat) sufi. Tarekat disini dimaknai dengan ketaatan yang cermat atas aturan-aturan Islam baik dalam ritual maupun masalah-masalah sosial, yakni dengan menjalani wira'i sebagai pandangan dunia di mana pelaku selalu mengindari perbuatan haram dan makruh ${ }^{22}$.

Pasar dalam hal ini memberikan peran sebagai tempat aktivitas ekonomi yaitu perdagangan. Dahulu pasar merupakan tempat pemukiman saudagar dan orang terpelajar kelas menengah. Di pasar ini terjadi komunikasi ekonomi, sosial, budaya dan agama sehingga dalam penyebaranya Islam terbawa melalui komunikasi yang dilakukan. Selain itu terdapat masjid yang berdiri di tengah pasar yang menjadi pusat kajian keIslaman, bentuk kegiatan ini berupa pengajian pengajian keagamaan. Dari pasar didatangkan buku buku dan literasi agama dari Arab dan persia yang nantinya dikirim ke pesantren untuk dikaji oleh santri dan disebarluaskan melalui dakwah.

Setelah penyebaran Islam sudah mulai meluas kemudian ulama-ulama pribumi yang sebelumnya belajar di timur tengah mengisi peran ulama-ulama yang berasal dari timur tengah dalam mengajarkan dan mengembangkan tradisi keilmuan di tanah melayu para ulama ini juga terampil dalam memberikan keterangan keagamaan melalui tulisan dan karya kitab dengan cirikhas menggunakan bahsa lokal yaitu bahasa melayu dan bahasa Jawa selain juga menggunakan bahsa Arab.

Produktifnya para tokoh dalam menulis karya berupa teks kitab, sehingga tradisi keilmuan di Aceh tumbuh subur pada abad ke 16 dan 17 diantaranya para tokoh ini adalah Hamzah Fansuri kemudian beberapa tokoh muridnya yaitu Syamsudin al Sumatrani, abdul jamal, Hasan Fansuri dan lain sebagainya. Beberapa hasil karya sastra mereka diantaranya berkenaan dengan doktrin wahdatul wujud yang bercorak filosofis intelektual.

Islam di tanah melayu diawali dari sebuah kerajaan bernama Samudra Pasai dan Aceh yang kemudian menyebarke wilayah-wilayah lain di kepulauan nusantara. Di kepulauan melayu pusat kekuasaan danperadaban Islam selain Aceh muncul. Ketika Aceh darussalam mengalami kemunduran pada $18 \mathrm{M}$ mulai ada kerjaan

\footnotetext{
${ }^{22}$ Muhamad Basyrul Muvid Amir Maliki Abitolkha, MELACAK TAREKAT-TAREKAT MUKTABAR DI NUSANTARA (Goresan Pena, 2020).
} 
palembang, Johor, Riau, Banjarmasin,Minangkabau dan lain lain. Salah satu bukti kebudayaan Islam ada adalah dengan adanya kitab-kitab keagamaan dan sastra Islam yang telah ditulis dalam bahasa melayu. Ada juga beberapa ajaran tassawuf yang sangat dominan dalam pemikiran keagamaan dan penulisan karya sastra ${ }^{23}$. Salah satu aliran tassawuf yang masih ada sampai sekarang adalah ratib saman di desa pulau tengah Kerinci Jambi. Diamna pelaksanaan ratib ini dilaksanakan sambil berdiri.

Riau juga merupakan bagian dari berkembangnya Islamisasi didaerah melayu, namun dalam pelaksanaan ajaran Islam ada tiga unsur yang berkambang yaitu: 1) Unsur Syari'i dalam agama Islam yaitu shalat, haji, zakat dan lainya, 2) Unsur yang berasal dari kepercayaan lama, seperti menyemah kampung, menurun lancang, mati tanah, dan tradisi perdukunan lainya, 3) Unsur yang berasal dari hasil integrasi Islam dan budaya yaitu kenduri, menzoarahi tempat keramat, dan lainya

Ketiga unsur ini terdapat hubungan yang erat dan saling terikat. Dalam masyarakat melayu riau tidak terdapat perbedaanperlakuan yang tegas anatara unsur yang berasal dari kepercayaan, karenaunsur yang berasal dari kepercayaan itu tiidak boleh berlawanan dengan unsur agama. Kedua unsur ini berkembang dan menyatu di tengah masyarakat dan memperkaya khazanah budaya melayu di riau. Unsur budaya lama telah diberinilai nilai kesilaman, dengan menggantikan simbol lama dengan simbol yang berbau Islam. bukan saja unsur dalam Islam populer yang mengandung ciri Islam namun unsur budaya lama juga mengandung ciri Islam, misalnya pengucapan mantera yang dimulai dengan bismillah dan diakhiri dengan syahadat.

Integrasi yang terjadi di masyarakat melayu tidak hanya masuk kedalam kegiatan dan interaksi masyarakat saja, bahkan dalam sistem pemerintahan juga dihiasi dengan nilai nilai Islam, misalnya ketika memilih seorang raja harus memenuhi beberapakriteri yang sudah di dasarkan. Raja Ali Haji menulis beberapa syarat seseorang ketika ingin menjadi pemimpin yaitu : 1) Muslim yang teguh dan memegang Islam, 2) Laki laki yang mukallaf dan merdeka, 3) Adil, 4) Mempunyai ijtihad yang elok, 5) Baik bicara, pendengaran dan penglihatan, 6) Mempunyai sifat berani, 7) Rajin dan berkemauan keras dalam menjalankan pekerjaan kebajikan ${ }^{24}$.

Syarat syarat ini diberlakukan di kerjaan melayu khususnya kerjaan siak. Selain ini pemberian gelar yang diawali dengan nama yang Islami kepada raja juga merupakan bentuk integrasi Islam dengan budaya masyarakat melayu misalnya Sultan Syarif Hasyim. Selain itu salah satu hal yang menggambarkan kerajaan melayu identik dengan Islam serta adanya keterpaduan ide dalam agama dan politik dapat ditemukan pada lambang negara yang dipakai oleh kesulatanan siak. Lambang kesultanan Siak ini berwujud dua kata Nabi saw. yang ditulis dalam huruf Arab

\footnotetext{
${ }^{23}$ Widhiya Ninsiana, "Islam Dan IntegrasI Soslal Dalam CermInan Masyarakat Nusantara," AKADEMIKA: Jurnal Pemikiran Islam 21, no. 2 (2016): 357-76.

${ }^{24}$ Mahdini, Etika Politik: Pandangan Raja Ali Haji Dalam Tsamarat Al-Muhimmah (Yayasan Pusaka Riau, 2000).
} 
melayu, posisi tulisan muhammad itu dibuat pipih dan bertindih atau bertangkup sehingga lambang kerultanan siakdinamakan dengan muhammadbertangkup ${ }^{25}$.

\section{Islam di Bagian Timur Indonesia.}

Pemyebaran Islam di bagian timur Indonesia diprakarsai oleh tokoh-tokoh muslim dari Jawa. Penyebaranya dilakukan di semenanjug selatan sulawesi, maluku, lombok dan papua.

Penyebaran Islam di lombok dilakukan oleh salah seorang murid sunan giri yang dikenal dengan nama sunan prapen. Raja Islam yang pertama di daerah madura barat merupakan seorang santri dari sunan kudus. Banjarmasin mengenal Islam karena hubunganya dengan kerajaan demak bintoro, kerajaan ternate dan tidore menjadi Islam lantaran sunan giri. Dan dari kerajaan ternate yang menjadi pintu gerbang penyebaran Islam sampai ke raja ampat di papua. Kemudian perkembangan Islam di makassarpun dapat ditelusuri karena hubunganya denganh ternate ${ }^{26}$.

Kebiasaan adat kerajaan diseulawesi selatan yaitu dalam hal penggunaan nama-nama Islam untuk membubuhkan gelar nama didepan namanya, kebiasaan ini dilakukan oleh para raja. Kemdudian pada saat shalat jum'at para khatib selalu mendoaakn keselamatan raja dan kerajaan dalam setiap khotbah yang dilakukanya.

Selain itu dengan kedatangan Islam menambah jumlah panngaderreng yang awalnya empat menjadi lima, panngaderreng sendiri merupakan rangkuman dari budaya yang ada di sulawesi selatan. Atau seseuatu yang menjadi pijakan perilaku dan kehidupan masyarakat makassar. Panggaderreng juga merupakan tumpuantradisi yang sudah lama ada di sulawesi selatan. Keempat komponen manngaderreng adalah, 1) ade' (adat) mengatur kehidupan rumah tangga, kehiduapn bermasyarakat dan bernegara, 2) bicara atau ketentuan yang menyangkut masalah peradilan, 3) rampang berrati pemisahan atau perumpamaan berfungsi untuk memberikan petunjuk tentang apa yang seharusnya dilakukan dan apa yang seharusnya tidak dilakukan, 4) wari' yang befungsi untuk menata masyarakat menurut hubungan kekerabatan dan keturunan

kedatangan Islam menambah satu komponen lagi yang memiliki tanggung Jawab dalam mengatur permasalahan keagamaan yaitu sara', sara' secara struktur dan pranata sosial diposisian setara dengan keempat panngaderreng yang telah ada sebelumnya ${ }^{27}$.

\section{Simpulan}

Perlu dipahami bahwa Integrasi yang terjadi dalam dunia Islam nusantara merupakan hasil pemikiran kaum elit, Walisongo yang merupakan jajaran kaum elit yang dari segi ilmu tidak perlu dipertanyakan lagi keahlianya ternyatajuga memiliki kecerdikan dengan mendekati para pemimpin kerajaan sehingga dalam pelaksanaan dakwah memiliki kedudukan, meskipun tetap merangkul dan objek utamanya

\footnotetext{
${ }^{25}$ A Luthfi, Hukum Dan Perubahan Struktur Kekuasaan: Pelaksanaan Hukum Islam Dalam Kesultanan Melayu Siak, 1901-1942 (Susqa Press, 1991).

${ }^{26}$ Ninsiana, "Islam Dan IntegrasI Soslal Dalam CermInan Masyarakat Nusantara."

${ }^{27}$ Sabara Nuruddin, "ISLAM DALAM TRADISI MASYARAKAT LOKAL DI SULAWESI SELATAN," MIMIKRI 4, no. 1 (2018): 50-67.
} 
adalah kaum kaum pinggiran. Kemudian pada masa sekarang juga sudah jelas terlihat bahwa proses integrasi Islam dan budaya nusantara juga dilakukan oleh kaum elit yang dengan kecerdasan dan kearifanya menanggapi tantangan masa depan diantaranya adalah KH Ahmad dahlan dengan gerakan Muhammadiyahnya, KH Hasyim Asy'ari dengan NU, M Hatta dan Syarifudin Prawiranegara dengan pemikrian ekonomi Islam. pada masa sekarang masih banyak pemikir muslim yang memberikan sumbangsih pemikiranya diantaranya adalah Mukti Ali,Harun Nasution, Nur Cholis Majdid, Azyumardi Azra, Abdurrahman Wahid. Halini merupakan suatu anugrah bagi bumi nusantara memiliki para pemikir muslim yang hebat.

Pemikiran muslim ini hendaknya dipelajari dan dimaknai sehingga tidak hanya pemikiran tokoh-tokoh terahulu yang kita pahami melalui jalan pikiran kita, karena perbadingan dan pengalaman pendidikan para tokoh dapat mencerminkan keberagaman dan beragamaan yang memang dibutuhkan di nusantara dengan begitu banyaknya perbdaaan yang dimiliki. Sehingga tercipta negara yang baldatun toyyibatun wa robbun ghofur.

\section{DAFTAR PUSTAKA}

Abdullah, Mudhofir. "Pribumisasi Islam Dalam Konteks Budaya Jawa Dan Integrasi Bangsa." Jurnal Indo-Islamika 4, no. 1 (2014): 67-90.

Al-Amri, Limyah, and Muhammad Haramain. "Akulturasi Islam Dalam Budaya Lokal.” KURIOSITAS: Media Komunikasi Sosial Dan Keagamaan 10, no. 2 (2017): 87-100.

Amir Maliki Abitolkha, Muhamad Basyrul Muvid. MELACAK TAREKAT-TAREKAT MUKTABAR DI NUSANTARA. Goresan Pena, 2020.

Bindel, L. Effects of Integrated Learning: Explicating a Mathematical Concept in Inquiry-Based Science Camps. Studien Zum Physik- Und Chemielernen. Logos Verlag Berlin, 2018.

Fuadi, A. Keragaman Dalam Dinamika Sosial Budaya Kompetensi Sosial Kultural Perekat Bangsa. Deepublish, 2020.

Geertz, C. The Religion of Java. Center for International Studies. Free Press, 1960.

Hakim, L. Pendidikan Islam Integratif: Best Practice Integrasi Pendidikan Agama Islam Dalam Kurikulum Pendidikan Tinggi. Gestalt Media, 2020.

Ismail, M S, and M S Sri Hartati. PENDIDIKAN KEWARGANEGARAAN: Konsep Dasar Kehidupan Berbangsa Dan Bernegara Di Indonesia. Penerbit Qiara Media, 2020.

Juddi, M F. KOMUNIKASI BUDAYA DAN DOKUMENTASI KONTEMPORER. Unpad Press, 2019.

King, V T, and W D Wilder. The Modern Anthropology of South-East Asia: An Introduction. Modern Anthropology of South-East Asia. RoutledgeCurzon, 2003.

Luthfi, A. Hukum Dan Perubahan Struktur Kekuasaan: Pelaksanaan Hukum Islam Dalam Kesultanan Melayu Siak, 1901-1942. Susqa Press, 1991.

Luthfi, Khabibi Muhammad. "Islam Nusantara: Relasi Islam Dan Budaya Lokal." SHAHIH: Journal of Islamicate Multidisciplinary 1, no. 1 (2016): 1-12. 
M, Jogiyanto Hartono. Metoda Pengumpulan Dan Teknik Analisis Data. Penerbit Andi, n.d.

Mahdini. Etika Politik: Pandangan Raja Ali Haji Dalam Tsamarat Al-Muhimmah. Yayasan Pusaka Riau, 2000.

Mudra, M A. Redefinisi Melayu: Upaya Menjembatani Perbedaan Konsep Kemelayuan Bangsa Serumpun, 2013.

Nata, A. Islam Dan Ilmu Pengetahuan. Prenada Media, 2018.

Ninsiana, Widhiya. "Islam Dan IntegrasI SosIal Dalam CermInan Masyarakat Nusantara." AKADEMIKA: Jurnal Pemikiran Islam 21, no. 2 (2016): 357-76.

Nuruddin, Sabara. "ISLAM DALAM TRADISI MASYARAKAT LOKAL DI SULAWESI SELATAN.” MIMIKRI 4, no. 1 (2018): 50-67.

Rabe-Hemp, C, V Garcia, G S Humiston, A M Schuck, S Strobl, A Shen, J Brown, et al. Women Policing across the Globe: Shared Challenges and Successes in the Integration of Women Police Worldwide. Rowman \\& Littlefield Publishers, 2019.

Rasyidin, A. Percikan Pemikiran Pendidikan: Dari Filsafat Hingga Praktik Pendidikan. Citapustaka Media Perintis, 2009.

Riyanto, S, and A A Hatmawan. Metode Riset Penelitian Kuantitatif Penelitian Di Bidang Manajemen, Teknik, Pendidikan Dan Eksperimen. Deepublish, 2020.

Sriyana, S.S.M.S. Antropologi Sosial Budaya. Penerbit Lakeisha, 2020.

Teuku Muttaqin Mansur, Sulaiman, Adli Abdullah, and Hasbi Ali. Ilmu Sosial Dan Budaya Dasar: Berbasis General Education. Syiah Kuala University Press, 2020.

Ujang Sumarwan, A.D.I.F.H. Metode Riset Bisnis Dan Konsumen Edisi Revisi. PT Penerbit IPB Press, 2018. 